\title{
Spirometric studies on normal Turkish subjects aged 8 to 20 years
}

\author{
NECATI AKGÜN AND HAMIT ÖZGÖN ÜL \\ From the Department of Physiology, Ege University Medical Faculty, Izmir, Turkey
}

\begin{abstract}
Total lung capacity and its subdivisions, maximal breathing capacity and forced expiratory volume in one second expressed as a percentage of the forced vital capacity, were measured in 130 male and 130 female normal Turkish subjects 8 to 20 years old to establish normal values. The subjects were from different socio-economic communities. Statistical analysis was performed to determine the relationship of the measurements to age and the physical characteristics of the body, and the best regression equations were found for predicting lung volumes and maximal breathing capacity. It was found that all physical characteristics were highly correlated with spirometric measurements. Best prediction formulae were found to be based on body surface area and height. All volumes and maximal breathing capacity were found, in general, to be higher in males. This sex difference in measurements became significant after 16-17 years of age. The difference in height between the two sexes also became significant after 16 years of age. In the same age group and in both sexes, taller subjects had higher lung volumes and maximal breathing capacity. These findings suggest that height and respiratory muscle power are the main factors of sex difference in the measurements. Vital capacity and maximal breathing capacity related to age in both sexes were compared with those of some previous studies and it was found that all data, except a few, fell within the $95 \%$ confidence limits of the present study. Similar observations were, in general, made when height was taken into consideration for comparison. The value of $\mathrm{FEV}_{1} / \mathrm{FVC} \%$ was altered little for the age group studied and its mean value was about $86 \cdot 6 \pm$ $4.2 \%$ for males and $87 \pm 4 \cdot 2 \%$ for females. There was no significant relationship between age or sex and RV/TLC $\%$ and the mean value of this parameter was $23.6 \pm 1.9$ for males and $25.5 \pm 1.6$ for females. There was a slight but clinically unimportant difference between the values of these two measurements and the value from the literature.
\end{abstract}

Since both static and dynamic lung function measurements have become standard procedures in evaluating pulmonary dysfunction, normal values and prediction formulae for these measurements have been established in several countries. These show a rather wide variation in individual values about the mean or predicted values due to many factors, including the particular segment of population studied. Therefore, it was decided to establish normal values for Turkish subjects. This report presents the data obtained for total lung capacity and its subdivisions, maximal breathing capacity and forced expiratory volume in one second, for normal Turkish subjects of both sexes, 8 to 20 years old.

\section{MATERIALS AND METHODS}

Lung function measurements were done on 130 male and 130 female subjects ranging in age from 8 to
20 years and taken from different economic and social communities, so that we felt that the wholf population was represented. All were healthy an had no history of chronic respiratory or cardiao disease. The physical characteristics of the subject? are listed in Table I.

Total lung capacity, inspiratory capacity, expiratory. reserve volume, vital capacity, maximal breathing capacity, and forced expiratory volume in one second were measured with a 9-litre spirometer. ${ }^{1}$ The $\mathrm{CO}$ absorbing canister was not removed during any of the tests. Functional residual capacity was measured by a closed-circuit helium dilution technique (Comro@ Forster, DuBois, Briscoe, and Carlsen, 1962), anf residual volume was calculated by subtracting the expiratory reserve volume from the functional resi= dua! capacity. Forced expiratory volume in ons

1Godart Pulmonet (Type 59004), which is a water-sealed spiro meter having no valves. Its kymograph is provided with tw speeds, 60 and $1,200 \mathrm{~mm} . / \mathrm{min}$. The frequency response of the spirometer is completely linear up to 80 breaths/minute 
second was expressed as a percentage of the forced vital capacity $\left(\mathrm{FEV}_{1} / \mathrm{FVC} \%\right)$. All volumes were corrected to BTPS.

The measurements were performed with the subjects in the sitting position. Before the measurements were taken, each subject was given information about the

T A B L E I

PHYSICAL CHARACTERISTICS OF THE SUBJECTS

\begin{tabular}{|c|c|c|c|c|c|}
\hline $\begin{array}{r}\text { Age } \\
\text { (yrs) }\end{array}$ & Sex & No. & $\begin{array}{l}\text { Height } \\
\text { (cm.) }\end{array}$ & $\begin{array}{l}\text { Weight } \\
\text { (kg.) }\end{array}$ & $\begin{array}{l}\underset{\left(\mathrm{m} .{ }^{2}\right)}{\text { BSA }} \\
\text { (1) }\end{array}$ \\
\hline 8 & $\underset{\mathbf{F}}{\mathbf{M}}$ & 10 & $\begin{array}{l}123 \cdot 2 \pm 4 \cdot 4 \\
123 \cdot 0+2 \cdot 6\end{array}$ & $\begin{array}{l}23 \cdot 6 \pm 2 \cdot 7 \\
22 \cdot 4+1 \cdot 9\end{array}$ & $0.902 \pm 0.064$ \\
\hline 9 & $\mathbf{M}$ & 10 & $126.5 \pm 4.9$ & $24 \cdot 6 \pm 3 \cdot 1$ & $0.936 \pm 0.074$ \\
\hline 10 & $\underset{\mathbf{M}}{\mathbf{F}}$ & 10 & $125 \cdot 5 \pm 3.5$ & $24 \cdot 1 \pm 2 \cdot 2$ & $0.922 \pm 0.055$ \\
\hline 10 & $\underset{\mathbf{F}}{\mathbf{M}}$ & $\begin{array}{l}10 \\
10\end{array}$ & $\begin{array}{l}132 \cdot 4 \pm 5 \cdot 8 \\
132 \cdot 6 \pm 3 \cdot 2\end{array}$ & $\begin{array}{l}28 \cdot 2 \pm 3 \cdot 3 \\
28 \cdot 5 \pm 2 \cdot 6\end{array}$ & $\begin{array}{l}1.025 \pm 0.079 \\
1.031 \pm 0.053\end{array}$ \\
\hline 11 & $\mathbf{M}$ & 10 & $138.2 \pm 3.6$ & $31.7 \pm 5.6$ & $1.109 \pm 0.093$ \\
\hline 12 & $\underset{\mathbf{M}}{\mathbf{F}}$ & $\begin{array}{l}10 \\
10\end{array}$ & $\begin{array}{l}137 \cdot 0 \pm 2 \cdot 7 \\
141 \cdot 9 \pm 4 \cdot 1\end{array}$ & $\begin{array}{l} \pm 2 \cdot 2 \\
\pm 2 \cdot 5\end{array}$ & $\begin{array}{l}1 \cdot 088 \pm 0.043 \\
1 \cdot 158 \pm 0.049\end{array}$ \\
\hline & $\mathbf{F}$ & 10 & $144 \cdot 0 \pm 6.2$ & 34 & $1.190 \pm 0.114$ \\
\hline 13 & $\mathbf{M}$ & 10 & $148 \cdot 8 \pm 5 \cdot 6$ & $38 \cdot \varepsilon$ & $1.278 \pm 0.059$ \\
\hline 14 & $\mathbf{M}$ & $\begin{array}{l}10 \\
10\end{array}$ & $\begin{array}{l}3 \pm 4 \cdot 5 \\
+4 \cdot 5\end{array}$ & $\begin{array}{l}42 \cdot 8 \pm 4 \cdot 0 \\
45 \cdot 3+5 \cdot 3\end{array}$ & $\begin{array}{l}1.348 \pm 0.076 \\
1.406+0.098\end{array}$ \\
\hline & 10 & 10 & $153.5 \pm 5.1$ & $45.5 \pm 8.6$ & $\begin{array}{l}1.406 \pm 0.098 \\
1.396 \pm 0.137\end{array}$ \\
\hline 15 & $\mathbf{M}$ & 10 & $162 \cdot 6 \pm 7 \cdot 1$ & $49 \cdot 7 \pm 5 \cdot 4$ & $1.514 \pm 0.112$ \\
\hline & & 10 & $153.5 \pm$ & & $1.396 \pm 0.137$ \\
\hline 16 & $\underset{\mathbf{F}}{\mathbf{M}}$ & $\begin{array}{l}10 \\
10\end{array}$ & $\begin{array}{l}170 \cdot 8 \pm 6 \cdot 4^{*} \\
158.2 \pm 4 \cdot 2\end{array}$ & $\begin{array}{l}59 \cdot 6 \pm 6.4 \\
49 \cdot 3 \pm 2.7\end{array}$ & $\begin{array}{l}1.695 \pm 0.114 \\
1.480 \pm 0.054\end{array}$ \\
\hline 17 & $\mathbf{M}$ & 10 & $169 \cdot 4 \pm 6 \cdot 7 *$ & $60.9 \pm 7 \cdot 7$ & $1.700 \pm 0.133$ \\
\hline & & 10 & $157 \cdot 4 \pm 3$ & $51.6 \pm$ & $1.502 \pm 0.062$ \\
\hline 18 & $\mathbf{M}$ & 10 & $172 \cdot 8 \pm 4 \cdot 1^{*}$ & $63.4 \pm 5.1$ & $1.755 \pm 0.086$ \\
\hline 19 & $\mathbf{F}$ & & $\begin{array}{l}158 \cdot 2 \pm 4 \cdot 2 \\
169 \cdot 8+5 \cdot 6 *\end{array}$ & $\begin{array}{l}49 \cdot 3 \pm 2 \cdot 7 \\
64 \cdot 3+8 \cdot 9\end{array}$ & $\begin{array}{l}1.480 \pm 0.054 \\
1.742+0.130\end{array}$ \\
\hline & $\mathbf{M}$ & 10 & $155.5 \pm 3.5$ & $\begin{array}{l}04 \cdot 3 \pm 8.9 \\
51 \cdot 5 \pm 4 \cdot 8\end{array}$ & $\begin{array}{l}1 . / 42 \pm 0.130 \\
1.488 \pm 0.076\end{array}$ \\
\hline 20 & $\underset{F}{M}$ & 10 & $170.8 \pm 6.4^{*}$ & $63.7 \pm$ & $1.743 \pm 0.107$ \\
\hline & & 10 & & 5 & .52 \\
\hline
\end{tabular}

The standing height was measured without shoes, and weight without heavy clothing.

Body surface area (BSA) was calculated from the Du Bois nomogram based on the formula $\mathrm{S}=\mathrm{W}^{0.425} \times \mathrm{H}^{0.725} \times 71 \cdot 84$. (Du Bois and Du Bois, 1916.)

Mean values $t 1 \mathrm{SD}$

* Difference in heights between sexes was significant $(P<0.001)$. tests, rested in a comfortable chair for at least 10 minutes, and became accustomed to breathing through the apparatus. Maximal breathing capacity was determined at a frequency chosen by each subject, who breathed as rapidly and as deeply as possible for 15 seconds. All measurements were made under the same laboratory conditions and repeated at least twice; the highest value obtained was used. The results were analysed by statistical methods ${ }^{2}$ to determine the relation of these measurements to age and body size.

\section{RESULTS}

ESTABLISHING NORMAL VALUES The results of some lung volume measurements as well as maximal breathing capacity were related to sex, age, weight, height, and body surface area (Tables II to V). Vital capacity, total lung capacity, functional residual capacity, residual volume, and maximal breathing capacity were found, in general, to be higher in males; this became significant $(P<0.05)$ after 16 years of age for vital capacity, total lung capacity, and maximal breathing capacity and after 17 for functional residual capacity and residual volume (Fig. 1, Table II). The difference in height between the sexes began after 14 years of age and became significant $(\mathrm{P}<$ 0.001) after 16 (Table I, Fig. 2). Furthermore, in the same age group for both sexes, taller subjects ${ }^{2}$ All statistical calculations were done by an IBM $360 / 50$ computer
at the Computer Center, University of California San Francisco
Medical Center. For stepwise multiple regression the BMDO2R
version of the Health Services Computer Facility, UCLA, of 9 April 1964 was used

T A B LE I I

TOTAL LUNG CAPACITY (TLC), VITAL CAPACITY (VC), FUNCTIONAL RESIDUAL CAPACITY (FRC), RESIDUAL VOLUME (RV), AND MAXIMAL BREATHING CAPACITY (MBC) IN RELATION TO AGE

\begin{tabular}{|c|c|c|c|c|c|c|c|}
\hline$\underset{\text { (yrs) }}{\text { Age }}$ & Sex & No. & $\begin{array}{l}\text { TLC } \\
\text { (ml.) }\end{array}$ & $\underset{\text { (ml.) }}{\mathrm{VC}}$ & $\begin{array}{l}\text { FRC } \\
\text { (ml.) }\end{array}$ & $\underset{\text { (ml.) }}{\mathbf{R V}}$ & $\underset{(1 . / \mathrm{min} .)}{\mathrm{MBC}}$ \\
\hline $\begin{array}{r}8 \\
9 \\
10 \\
11 \\
12 \\
13 \\
14 \\
15 \\
16 \\
17 \\
18 \\
19 \\
20\end{array}$ & $\begin{array}{c}\mathbf{M} \\
\mathbf{F} \\
\mathbf{M} \\
\mathbf{F} \\
\mathbf{M} \\
\mathbf{F} \\
\mathbf{M} \\
\mathbf{F} \\
\mathbf{M} \\
\mathbf{F} \\
\mathbf{M} \\
\mathbf{F} \\
\mathbf{M} \\
\mathbf{F} \\
\mathbf{M} \\
\mathbf{F} \\
\mathbf{M} \\
\mathbf{F} \\
\mathbf{M} \\
\mathbf{F} \\
\mathbf{M} \\
\mathbf{F} \\
\mathbf{M} \\
\mathbf{F} \\
\mathbf{M} \\
\mathbf{F}\end{array}$ & $\begin{array}{l}10 \\
10 \\
10 \\
10 \\
10 \\
10 \\
10 \\
10 \\
10 \\
10 \\
10 \\
10 \\
10 \\
10 \\
10 \\
10 \\
10 \\
10 \\
10 \\
10 \\
10 \\
10 \\
10 \\
10 \\
10 \\
10\end{array}$ & $\begin{array}{l}2,233 \pm 240 \\
2,122 \pm 190 \\
2,379 \pm 297 \\
2,270 \pm 219 \\
2,723 \pm 320 \\
2,598 \pm 127 \\
3,028 \pm 279 \\
2,788 \pm 238 \\
3,204 \pm 345 \\
3,090 \pm 331 \\
3,603 \pm 365 \\
3,659 \pm 414 \\
4,183 \pm 433 \\
3,880 \pm 518 \\
4,802 \pm 716 \\
4,448 \pm 557 \\
5,527 \pm 747 \dagger \\
4,581 \pm 397 \\
5,816 \pm 644 \ddagger \\
4,641 \pm 242 \\
6,328 \pm 576 \ddagger \\
4,777 \pm 462 \\
6,375 \pm 823 \ddagger \\
4,503 \pm 326 \\
6,381 \pm 746 \ddagger \\
4,475 \pm 452\end{array}$ & $\begin{array}{l}1,682 \pm 200 \\
1,577 \pm 180 \\
1,794 \pm 243 \\
1,699 \pm 180 \\
2,059 \pm 273 \\
1,916 \pm 105 \\
2,298 \pm 234 \\
2,054 \pm 211 * \\
2,450 \pm 301 \\
2,310 \pm 280 \\
2,778 \pm 282 \\
2,755 \pm 357 \\
3,200 \pm 366 \\
2,884 \pm 361 \\
3,668 \pm 575 \\
3,350 \pm 482 \\
4,307 \pm 575 \ddagger \\
3,438 \pm 362 \\
4,491 \pm 551 \\
3,458 \pm 210 \ddagger \\
4,804 \pm 431 \ddagger \\
3,522 \pm 426 \\
4,821 \pm 686 \ddagger \\
3,314 \pm 313 \\
4,884 \pm 637 \ddagger \\
3,291 \pm 366\end{array}$ & $\begin{array}{l}1,125 \pm 114 \\
1,084 \pm 101 \\
1,192 \pm 151 \\
1,141 \pm 99 \\
1,369 \pm 125 \\
1,357 \pm 80 \\
1,522 \pm 85 \\
1,444 \pm 98 \\
1,584 \pm 127 \\
1,581 \pm 140 \\
1,770 \pm 196 \\
1,843 \pm 166 \\
2,084 \pm 263 \\
1,974 \pm 286 \\
2,384 \pm 375 \\
2,242 \pm 238 \\
2,700 \pm 505 \\
2,232 \pm 198 \\
2,955 \pm 349+ \\
2,395 \pm 101 \\
3,286 \pm 432+ \\
2,487 \pm 162 \\
3,300 \pm 389+ \\
2,342 \pm 109 \\
3,265 \pm 444+ \\
2,335 \pm 211\end{array}$ & $\begin{array}{c}551 \pm 51 \\
549 \pm 46 \\
583 \pm 62 \\
571 \pm 50 \\
663 \pm 62 \\
682 \pm 32 \\
730 \pm 49 \\
734 \pm 36 \\
754 \pm 64 \\
780 \pm 55 \\
825 \pm 93 \\
904 \pm 71 * \\
984 \pm 150 \\
996 \pm 171 \\
1,134 \pm 172 \\
1,098 \pm 90 \\
1,220 \pm 207 \\
1,143 \pm 88 \\
1,325 \pm 161 * \\
1,184 \pm 49 \\
1,523 \pm 199 \ddagger \\
1,255 \pm 76 \\
1,553 \pm 234 \ddagger \\
1,190 \pm 38 \\
1,497 \pm 133 \ddagger \\
1,184 \pm 110\end{array}$ & $\begin{array}{c}46 \pm 5_{+}^{+} \\
36 \pm 4 \\
53 \pm 7^{*} \\
45 \pm 8 \\
58 \pm 9 \\
52 \pm 7 \\
69 \pm 11 \\
61 \pm 6 \\
73 \pm 8 \\
70 \pm 10 \\
79 \pm 9 \\
75 \pm 10 \\
88 \pm 14 \\
83 \pm 10 \\
111 \pm 22 \\
95 \pm 10 \\
124 \pm 19+ \\
101 \pm 11 \\
125 \pm 16_{+}^{+} \\
100 \pm 8 \\
133 \pm 18+ \\
100 \pm 12 \\
136 \pm 18+ \\
98 \pm 11 \\
141 \pm 13 \ddagger \\
95 \pm 11\end{array}$ \\
\hline
\end{tabular}



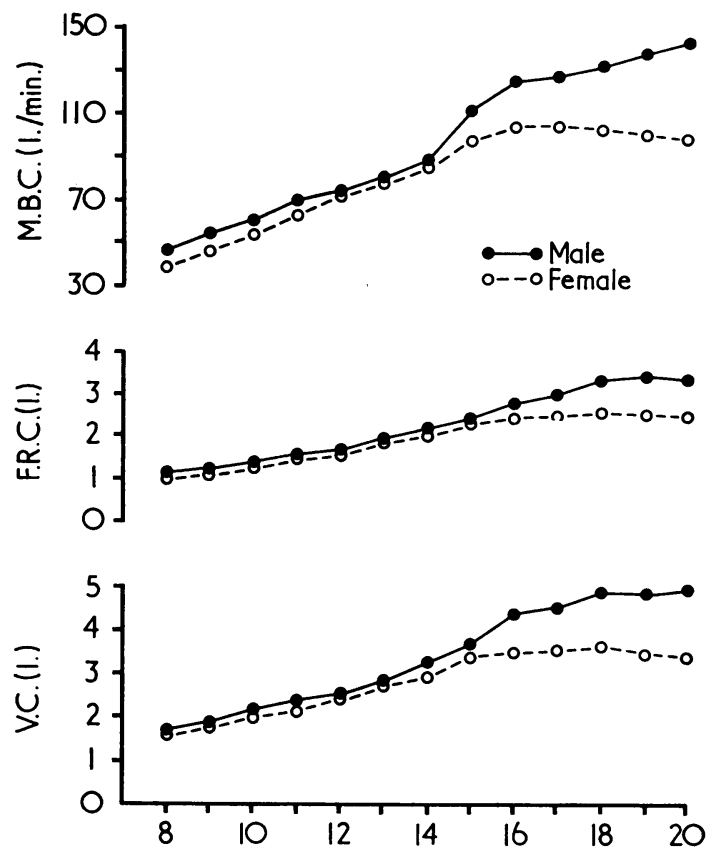

Age (years)

FIG. 1. Vital capacity, functional residual capacity, and maximal breathing capacity in relation to age in male and female subjects. Since total lung capacity and residual volume showed the same trend as vital capacity and functional residual capacity, respectively, they are not shown. Heights of females were smaller at 1920 years of age than for those at 18. This factor might have caused the downslope in the last part of the curve. had higher lung volumes and maximal breathing capacity. In spite of a tendency for the values fof vital capacity, total lung capacity, and maxim breathing capacity in the females to be somewhat lower within the same height group (Fig. 3, Tabde IV), only the differences seen in groups $134-138$ $\mathrm{cm}$. and $159-163 \mathrm{~cm}$. were almost uniformly sig. nificant. For the other height groups, a significant difference was seen only occasionally.

Because of a large variation around the meara, when they were expressed as absolute values, in

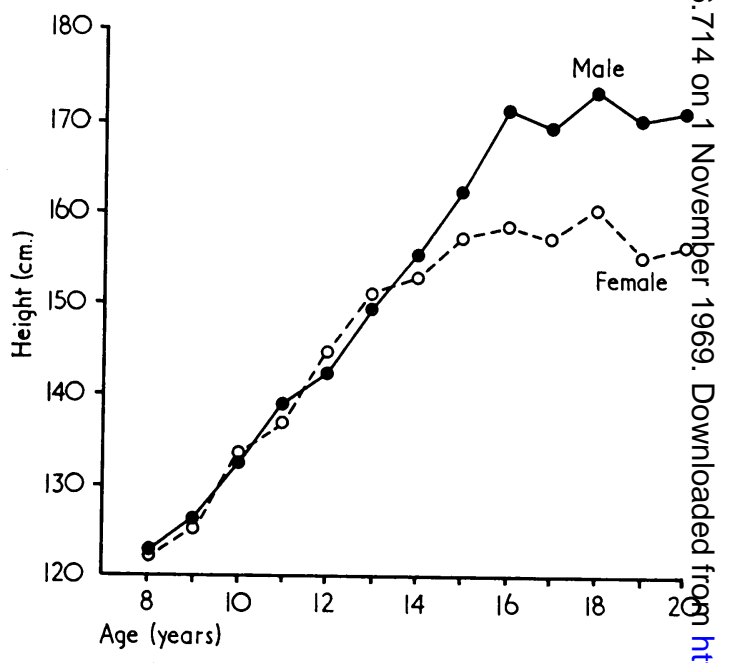

FIG. 2. Relationship between height and age in males amd females.

T A B L E I I I

TOTAL LUNG CAPACITY, VITAL CAPACITY FUNCTIONAL RESIDUAL CAPACITY, RESIDUAL VOLUME, AND MAXIMAX TOTAL LUNG CAPACITY, VITAL CAPACATHING CAPACITY IN RELATION TO WEIGHT

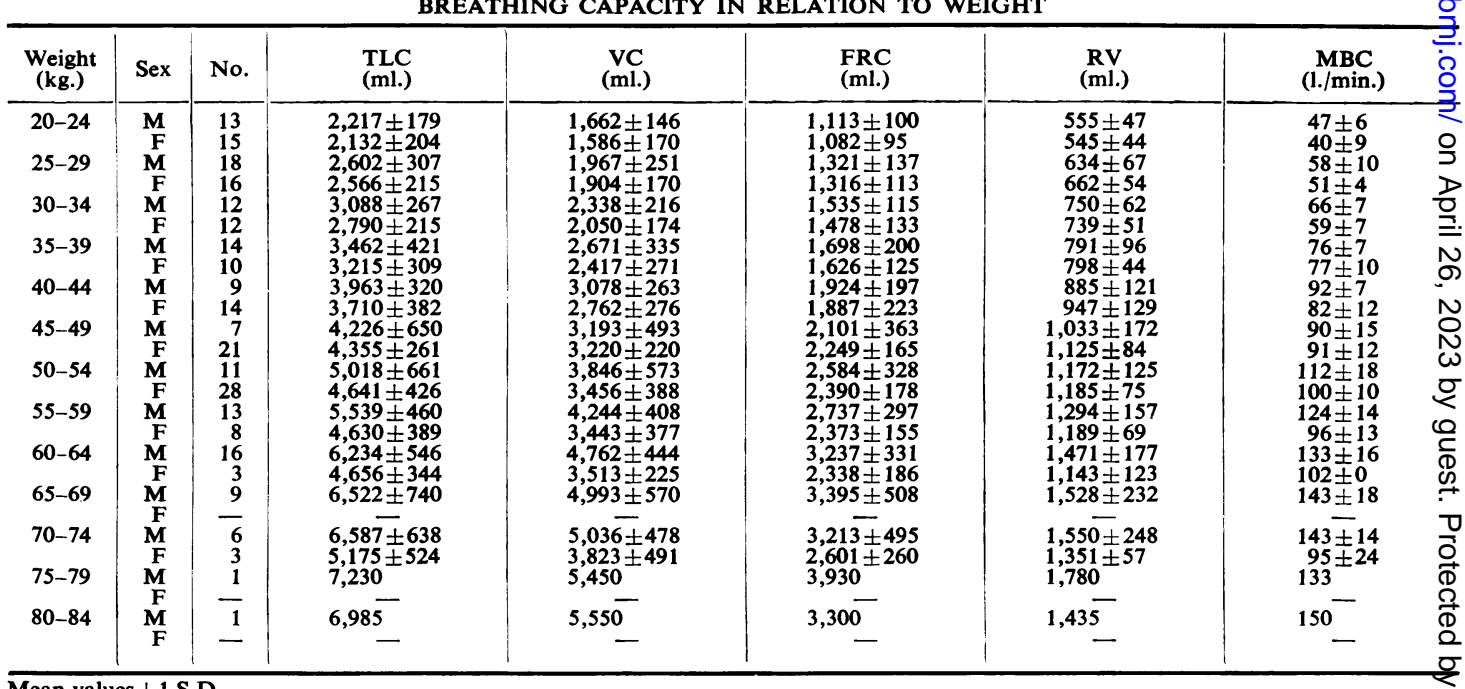


T A B LE I V

TOTAL LUNG CAPACITY, VITAL CAPACITY, FUNCTIONAL RESIDUAL CAPACITY, RESIDUAL VOLUME, AND MAXIMAL BREATHING CAPACITY IN RELATION TO STANDING HEIGHT

\begin{tabular}{|c|c|c|c|c|c|c|c|}
\hline $\begin{array}{c}\text { Height } \\
\text { (cm.) }\end{array}$ & Sex & No. & $\begin{array}{l}\text { TLC } \\
\text { (ml.) }\end{array}$ & $\begin{array}{l}\mathrm{VC} \\
\text { (ml.) }\end{array}$ & $\begin{array}{l}\text { FRC } \\
\text { (ml.) }\end{array}$ & $\underset{\text { (ml.) }}{\mathrm{RV}}$ & $\underset{\text { (1./min.) }}{\text { MBC }}$ \\
\hline $119-123$ & $\mathbf{M}$ & 9 & $2,174 \pm 186^{*}$ & $1,639 \pm 165$ & $1,083 \pm 79$ & $535 \pm 30$ & $45 \pm 5^{*}$ \\
\hline & $\mathbf{F}$ & 8 & $2,007 \pm 123$ & $1,491 \pm 120$ & $1,016 \pm 45$ & $515 \pm 7$ & $37 \pm 7$ \\
\hline $124-128$ & $\underset{\mathbf{M}}{\mathbf{M}}$ & 9 & $2,268 \pm 135$ & $1,701 \pm 113$ & $1,156 \pm 84$ & $567 \pm 44$ & $51 \pm 4$ \\
\hline $129-133$ & $\underset{\mathbf{M}}{\mathbf{F}}$ & 10 & $\begin{array}{l}2,290 \pm 147 \\
2,649 \pm 199 *\end{array}$ & $\begin{array}{l}1,710 \pm 130 \\
2,002 \pm 181\end{array}$ & $\begin{array}{l}1,161 \pm 60 \\
1,345 \pm 78\end{array}$ & $\begin{array}{l}580 \pm 33 \\
647 \pm 38\end{array}$ & $\begin{array}{l}41 \pm 6 \neq \\
56 \pm 7\end{array}$ \\
\hline & $F$ & 10 & $2,519 \pm 114$ & $1,856 \pm 98$ & $1,298 \pm 63$ & $663 \pm 29$ & $51 \pm 5$ \\
\hline $134-138$ & $\mathbf{M}$ & 9 & $3,059 \pm 173$ & $2,340 \pm 154 \Omega$ & $1,504 \pm 66^{*}$ & $718 \pm 35$ & $69 \pm 7 \dagger$ \\
\hline 139-143 & $\underset{\mathbf{M}}{\mathbf{F}}$ & $\begin{array}{l}10 \\
12\end{array}$ & $\begin{array}{l}2,713 \pm 154 \\
3,135 \pm 318\end{array}$ & $\begin{array}{l}1,996 \pm 142 \\
2,386 \pm 291\end{array}$ & $\begin{array}{l}1,424 \pm 68 \\
1,559 \pm 113\end{array}$ & $\begin{array}{l}717 \pm 28 \\
749 \pm 35\end{array}$ & $\begin{array}{l}60 \pm 5 \\
72 \pm 10\end{array}$ \\
\hline & $\mathbf{F}$ & 5 & $2,949 \pm 145$ & $2,184 \pm 134$ & $1,528 \pm 37$ & $765 \pm 25$ & $61 \pm 10$ \\
\hline $144-148$ & $\mathbf{M}$ & 6 & $3,398 \pm 394$ & $2,600 \pm 298$ & $1,687 \pm 197$ & $797 \pm 102$ & $74 \pm 6$ \\
\hline $149-153$ & $\underset{\mathbf{M}}{\mathbf{F}}$ & $\begin{array}{r}10 \\
9\end{array}$ & $\begin{array}{l}3,246 \pm 247 \\
3,766 \pm 341\end{array}$ & $\begin{array}{l}2,422 \pm 198 \\
2,911 \pm 322\end{array}$ & $\begin{array}{l}1,660 \pm 128 \\
1,831 \pm 122\end{array}$ & $\begin{array}{l}824 \pm 63 \\
854 \pm 50 \dagger\end{array}$ & $\begin{array}{l}71 \pm 8 \\
84 \pm 12\end{array}$ \\
\hline $154-158$ & $\mathbf{F}$ & 20 & $3,894 \pm 353$ & $2,893 \pm 228$ & $1,994 \pm 226^{*}$ & $1,002 \pm 145$ & $85 \pm 11$ \\
\hline $154-158$ & $\underset{\mathbf{F}}{\mathbf{M}}$ & $\begin{array}{r}9 \\
34\end{array}$ & $\begin{array}{l}4,195 \pm 308 \\
4,445+383\end{array}$ & $\begin{array}{l}3,201 \pm 205 \\
3,292 \pm 306\end{array}$ & $\begin{array}{l}2,083 \pm 207 \ddagger \\
2,304 \pm 194\end{array}$ & $\begin{array}{c}994 \pm 148 \\
1,153 \pm 1078\end{array}$ & $\begin{array}{l}88 \pm 12 \\
95 \pm 9\end{array}$ \\
\hline $159-163$ & $\underset{\mathbf{M}}{\mathbf{M}}$ & 10 & $5,111 \pm 601^{*}$ & $3,844 \pm 514$ & $2,600 \pm 284$ & $1,227 \pm 153$ & $119 \pm 16$ \\
\hline $164-168$ & $\mathbf{M}$ & $\begin{array}{l}17 \\
13\end{array}$ & $\begin{array}{l}4,665 \pm 295 \\
5,735 \pm 686\end{array}$ & $\begin{array}{l}3,457 \pm 270^{*} \\
4,392 \pm 527\end{array}$ & $\begin{array}{l}2,393 \pm 153^{*} \\
2,955 \pm 401\end{array}$ & $\begin{array}{l}1,196 \pm 72 \\
1,361 \pm 235\end{array}$ & $\begin{array}{r}98 \pm 115 \\
121 \pm 15\end{array}$ \\
\hline & $\mathbf{F}$ & 4 & $5,228 \pm 261$ & $4,065 \pm 201$ & $2,555 \pm 85^{*}$ & $1,163 \pm 63$ & $110 \pm 12$ \\
\hline $169-173$ & $\underset{\mathbf{F}}{\mathbf{M}}$ & $\begin{array}{r}19 \\
2\end{array}$ & $\begin{array}{l}5,944 \pm 694 \\
5,407 \pm 519\end{array}$ & $\begin{array}{l}4,583 \pm 562 \\
4,072 \pm 449\end{array}$ & $\begin{array}{l}2,962 \pm 427 \\
2,675 \pm 247\end{array}$ & $\begin{array}{l}1,361 \pm 180 \\
1,335 \pm 70\end{array}$ & $\begin{array}{l}131 \pm 17 \\
112 \pm 14\end{array}$ \\
\hline 174-178 & $\mathbf{M}$ & 11 & $6,616 \pm 634$ & $5,001 \pm 502$ & $3,473 \pm 389$ & $1,615 \pm 183$ & $139 \pm 21$ \\
\hline $179-183$ & $\underset{\mathbf{F}}{\mathbf{M}}$ & 5 & $6,636 \pm 747$ & $5,188 \pm 544$ & $3,317 \pm 613$ & $1,447 \pm 234$ & $145 \pm 13$ \\
\hline
\end{tabular}

Mean values $\pm 1 \mathrm{SD}:{ }^{*} \mathrm{P}<0.05 ; \dagger \mathrm{P}<0.01 ; \ddagger \mathrm{P}<0.005 ; \mathrm{S} \mathrm{P}<0.001$.

T A B L E V

TOTAL LUNG CAPACITY, VITAL CAPACITY, FUNCTIONAL RESIDUAL CAPACITY, RESIDUAL VOLUME, AND MAXIMAL BREATHING CAPACITY IN RELATION TO BODY SURFACE AREA

\begin{tabular}{|c|c|c|c|c|c|c|c|}
\hline $\begin{array}{c}\text { Body Surface } \\
\text { Area }\left(\mathrm{m} .^{2}\right)\end{array}$ & Sex & No. & $\begin{array}{l}\text { TLC } \\
\text { (ml.) }\end{array}$ & $\begin{array}{l}\text { VC } \\
\text { (ml.) }\end{array}$ & $\begin{array}{l}\text { FRC } \\
\text { (ml.) }\end{array}$ & $\underset{(\mathrm{ml} .)}{\mathrm{RV}}$ & $\begin{array}{c}\mathrm{MBC} \\
(1 . / \mathrm{min} .)\end{array}$ \\
\hline $\begin{array}{c}0.750-1.050 \\
1.051-1.351 \\
1.352-1.652 \\
1.653-1.953 \\
1.987\end{array}$ & $\begin{array}{c}\mathbf{M} \\
\mathbf{F} \\
\mathbf{M} \\
\mathbf{F} \\
\mathbf{M} \\
\mathbf{M} \\
\mathbf{M}\end{array}$ & $\begin{array}{r}29 \\
31 \\
32 \\
29 \\
30 \\
65 \\
38 \\
5 \\
1\end{array}$ & $\begin{array}{l}2,402 \pm 298 \\
2,335 \pm 274 \\
3,317 \pm 393 \\
3,119 \pm 356 * \\
4,794 \pm 749 \\
4,473 \pm 412 \\
6,295 \pm 645 \\
4,988 \pm 508 \\
6,985\end{array}$ & $\begin{array}{l}1,811 \pm 242 \\
1,732 \pm 208 \\
2,541 \pm 330 \\
2,320 \pm 287 \dagger \\
3,661 \pm 603 \ddagger \\
3,325 \pm 349 \\
4,819 \pm 4925 \\
3,707 \pm 413 \\
5,550\end{array}$ & $\begin{array}{l}1,211 \pm 145 \\
1,196 \pm 147 \\
1,638 \pm 171 \\
1,607 \pm 167 \\
2,413 \pm 413 \\
2,301 \pm 207 \\
3,214 \pm 445 \\
2,488 \pm 273 \\
3,300\end{array}$ & $\begin{array}{c}591 \pm 65 \\
603 \pm 73 \\
776 \pm 74 \\
799 \pm 80 \\
1,132 \pm 190 \\
1,145 \pm 102 \\
1,475 \pm 216 * \\
1,281 \pm 130 \\
1,435\end{array}$ & $\begin{array}{c}52 \pm 9+ \\
45 \pm 10 \\
74 \pm 11 \\
70 \pm 12 \\
105 \pm 19 \ddagger \\
95 \pm 12 \\
136 \pm 17 \S \\
97 \pm 17 \\
150\end{array}$ \\
\hline
\end{tabular}

Mean values \pm 1 SD. $\quad$ P values are the same as those shown in Table IV.

T A B L E V I

CORRELATION COEFFICIENTS OF PULMONARY FUNCTION MEASUREMENTS TO AGE, WEIGHT, STANDING HEIGHT, AND BODY SURFACE AREA IN BOTH SEXES

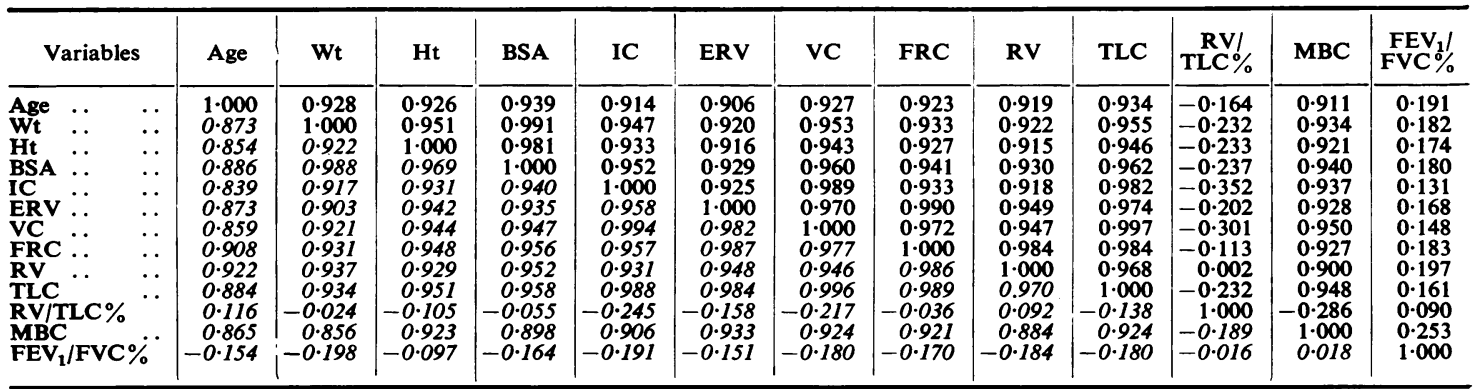

Normal figures for males; italic figures for females.

$\mathrm{Ht}=$ height, $\mathrm{Wt}=$ weight, $\mathrm{BSA}=$ body surface area, $\mathrm{IC}=$ inspiratory capacity, $\mathrm{ERV}=$ expiratory reserve volume, $\mathrm{FEV} / \mathrm{FVC} \%=$ forced expiratory volume in 1 second as percentage of the forced vital capacity. Other abbreviations as in Table II.

Values less than 0.174 are not significant at $P<0.05$; values less than 0.228 are not significant at $P<0.01$ 

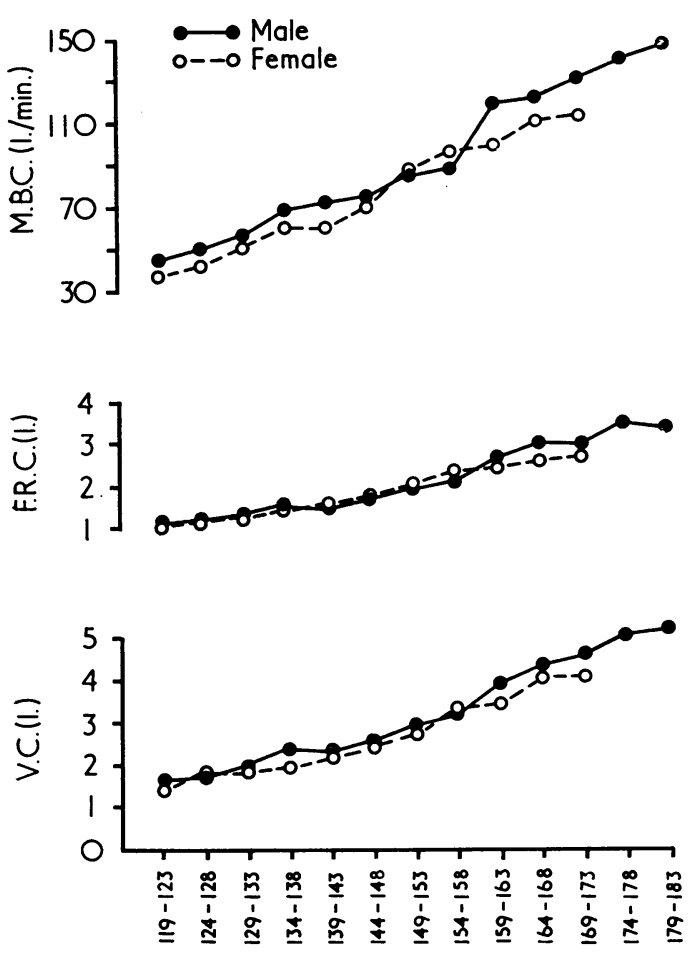

Height $(\mathrm{cm}$ )

FIG. 3. Vital capacity, functional residual capacity, and maximal breathing capacity in relation to height in males and females. Since total lung capacity and residual volume showed the same trend as vital capacity and functional residual capacity respectively, they are not shown. spiratory capacity and expiratory reserve volume were expressed as percentages of vital capacity and their mean values were about 65 and $35 \%$ respectively in both sexes.

Correlation coefficients between all the measurements and physical characteristics are given in $\vec{\circ}$ Table VI : all physical characteristics and age are highly corralated with each other and also with $\overrightarrow{\vec{\omega}}$ spirometric measurements in both sexes. Residual $O$ volume expressed as a percentage of total lung $\overrightarrow{\vec{x}}$ capacity (RV/TLC\%) was not changed by age, i height, weight, and body surface area in females. It was barely significantly reduced by an increase $\checkmark$ in weight, height, and body surface area in males $\vec{A}$ (Table VI). Its mean value was $23.6 \pm 1.9^{3}$ (maxi-음 mum 28.0 ; minimum 19.0 ) for males and $25.5 \pm-$ $1 \cdot 6^{3}$ (maximum 29.0 ; minimum 22.0 ) for females ; $z$ the difference between the sexes was not significant. $\mathrm{FEV}_{1} / \mathrm{FVC} \%$ in males was significantly 3 $(\mathrm{P}<0.05)$ related to age, height, weight, and body surface area, but the relationship was unimpor- $\vec{\odot}$ tant (Table VI). In females, there was also a sig- $\stackrel{\circ}{\circ}$ nificant $(\mathbf{P}<0.05)$, but unimportant, negative. correlation between this measurement and weight (Table VI). The mean value was $86 \cdot 6 \pm 4 \cdot 2^{3}$ (maximum 96.5 ; minimum 78.2) for males and $87.0 \pm$ $4 \cdot 2^{3}$ (maximum 97.0 ; minimum 78.3 ) for females. Again this difference was not significant.

PREDICTION FORMULAE Best regression equations for predicting some of the lung function measurements are shown in Table VII. Body surface area-

${ }^{3}$ With one standard deviation.

TA B LE VII

BEST REGRESSION EQUATIONS TO PREDICT EACH LUNG FUNCTION MEASUREMENT

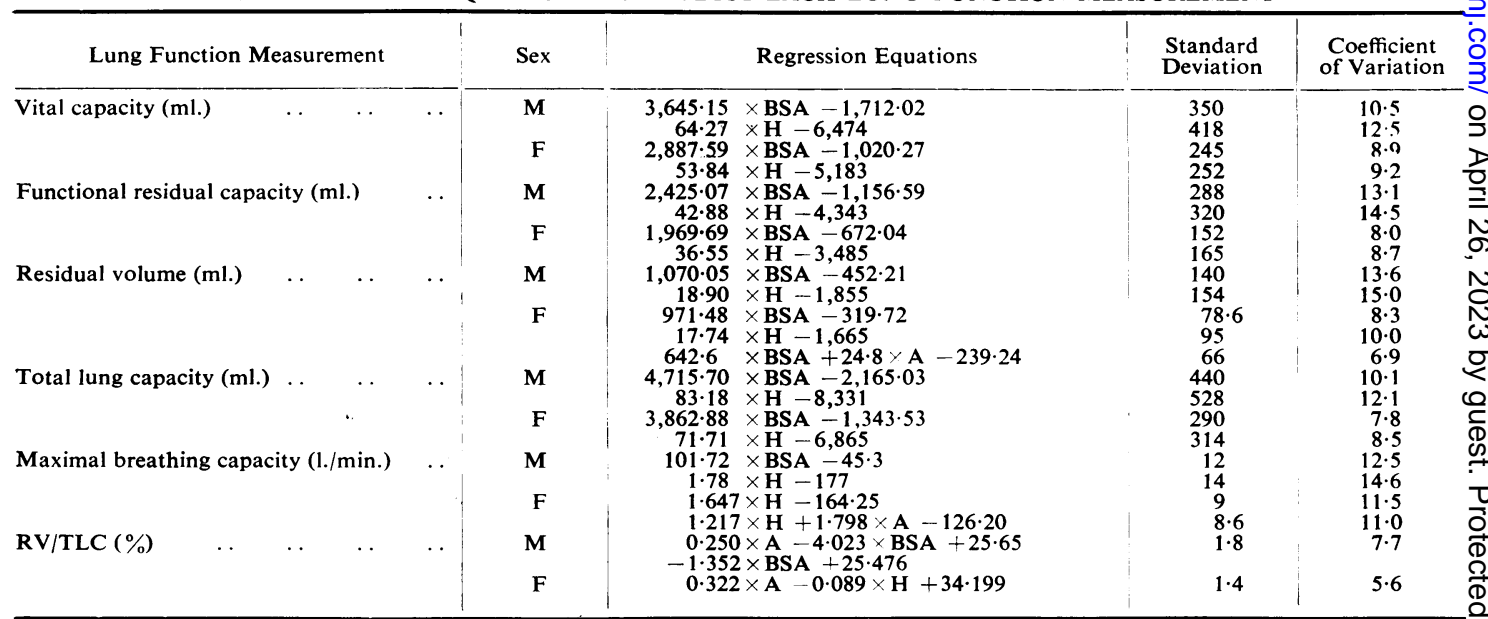

The constants of the regression equations are based upon the following units of measurements: the lung volumes $=$ ml., maximal breathing $\sigma$ capacity $=1 . / \mathrm{min} ., \mathrm{BSA}=\mathrm{m}^{2}$, height $=\mathrm{cm}$., age $=$ years. 
was the best standard of reference for all lung volumes and maximal breathing capacity, except that height was best in females for maximal breathing capacity. These findings were, in general, in good agreement with those of Emerson and Green (1921), Needham, Rogan, and McDonald (1954), West (1920), and Dreyer (1919). Analysis of covariance showed that there was a significant difference between the regression lines of the sexes. In males, there was no significant increase in the accuracy of prediction by using a multiple regression equation including age or height or both as standards of reference in addition to body surface area. In females, slightly more accuracy was gained by using a multiple regression equation with body surface area and age for residual volume and height and age for maximal breathing capacity. Therefore their regression equations based on these standards are also given in Table 'VII. Since height is less frequently below normal in several pathological conditions, it is now more commonly preferred to the complicated measurement of body surface area, and there was no significant difference between the results when body surface area or height was used alone as a basis of prediction; the regression equations based on height are also given in Table VII for all lung volumes and maximal breathing capacity.

\section{DISCUSSION}

The present study showed that all physical characteristics are highly correlated with spirometric measurements, probably because in a group of normal growing subjects height, weight, and body surface area are all highly correlated with each other. These findings are in close agreement with other data (Needham et al., 1954 ; Emerson and Green, 1921 ; Baldwin, 1928 ; Kennedy, ThursbyPelham, and Oldham, 1957 ; Lyons, Tanner, and Picco, 1960 ; Morse, Schlutz, and Cassels, 1952 ; Bjure, 1963 ; Strang, 1959 ; Jones, 1955 ; Tatai, 1955) and were expected. Vital capacity, total lung capacity, and maximal breathing capacity, in general, were significantly higher in males after 16 years of age. This difference can be explained by the height factor, because the height difference also became significant after 16 . In the same age group and in both sexes, taller subjects had higher lung volumes and maximal breathing capacity. The height factor in lung function measurements is well known and has already been noted by many investigators (Bhattacharya and Banerjee, 1966 ; Bjure, 1963 ; Engström et al.,
1956 ; Engström, Karlberg, Kraepelien, and Wengler, 1958; Emerson and Green, 1921 ; Baldwin, 1928 ; Kennedy et al., 1957 ; Turner and McLean, 1951 ; Ferris and Smith, 1953 ; Lyons et al., 1960 ; Morse et al., 1952 ; Strang, 1959 ; Tatai, 1955). When height was taken into account there was a good agreement between the present values and the values obtained from comparable groups by others (Ferris and Smith, 1953 ; Ferris, Whittenberger, and Gallagher, 1952; Stewart, 1922; Strang, 1959). However, the findings of Bhattacharya et al. were markedly below the present values for corresponding age and height groups in both sexes. As they mentioned, these low values can be explained by the lack of physical activity of their subjects. Jones (1955) and Engström et al. (1956) measured the vital capacity of children between 6 and 14 years of age and did not find a significant difference between the sexes in this age group ; their results can be explained by the similar height and muscular development in males and females at this particular age period.

Ferris and Smith (1953) and Ferris et al. (1952) studied vital capacity and maximal breathing capacity on subjects 5-18 years of age and found

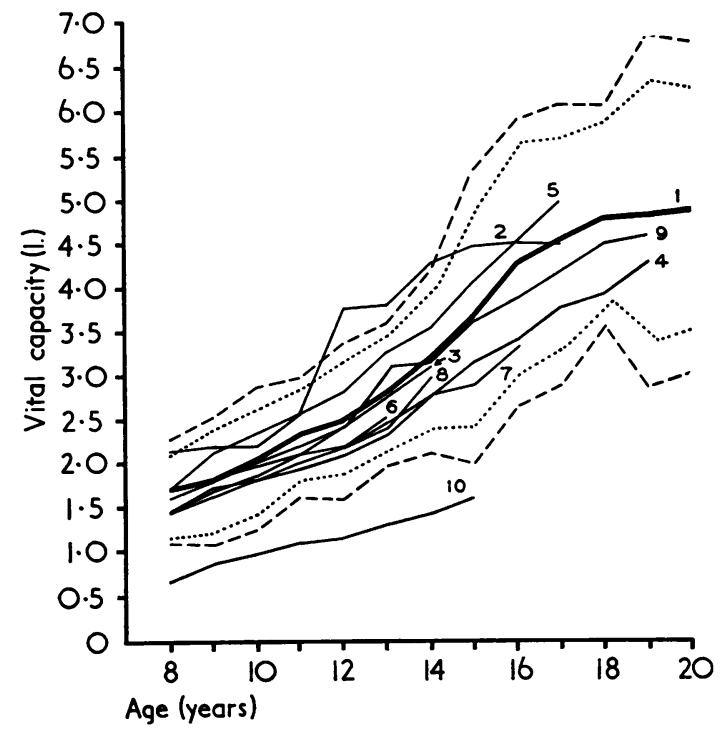

FIG. 4. Relationship of vital capacity of male subjects to age. Comparison of present mean values with those of other authors. Dashed lines are $95 \%$ tolerance limits with probability of 0.05 of being wrong and dotted lines are $95 \%$ confidence limits of the present study. 1, Present study; 2, Ferris and Smith (1953); 3, Lyons et al. (1960); 4, Stewart (1922); 5, Strang (1959); 6, Jones (1955); 7, Tatai (1955); 8, Kennedy et al. (1957); 9, Needham et al. (1954); and 10, Emerson and Green (1921). 
the values markedly higher in males than in females for taller subjects. Stewart (1922) also studied a large number of subjects from 4 to 19 years of age and found that vital capacity was greater for the males than for females of corresponding height and that this difference became more marked for taller subjects. The observations of Bjure (1963), Tatai (1955), and Bhattacharya and Banerjee (1966) were the same. Bjure compared males and females $160 \mathrm{~cm}$. and taller, and found significant differences in spirometric values. By chance, there were fewer taller female subjects in the present study and it was, therefore, not possible to show more clearly whether a difference existed in lung function measurements between males and females in the taller groups. However, Fig. 3 shows that values for males and females diverge more in taller subjects.

Although Lyons et al. (1960) and Ferris et al. (1952) have observed an abrupt increase in vitai capacity for adolescent males, it was not noted (Fig. 1) for either sex in the present study. The results for vital capacity related to age in both sexes were compared with those of some previous studies (Figs 4 and 5) and rather good agreement

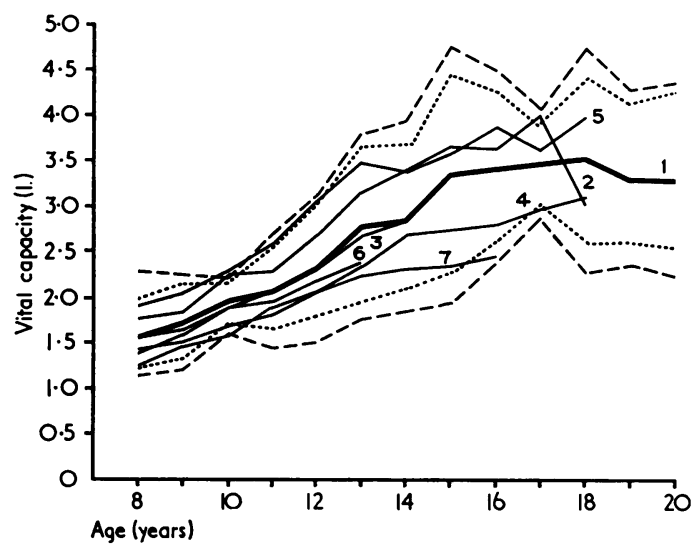

FIG. 5. Relationship of vital capacity of female subjects to age. Comparison of present mean values with those of other authors. Dashed and dotted lines as in Figure 4. 1, Present study; 2, Ferris and Smith (1953); 3, Lyons et al. (1960); 4, Stewart (1922); 5, Strang (1959); 6, Jones (1955); and, 7, Tatai (1955).

was found. All curves, except two, fell within the $95 \%$ confidence limits of the present study. The values of Ferris et al. (1952) for male subjects were higher than those found by others and were even above the confidence and tolerance limits between 12 and 14 years of age. This can be explained by their method in which the valves and
$\mathrm{CO}_{2}$ absorbing canister were removed and by the high level of physical fitness of their subjects. TRe data of Emerson and Green (1921) were very low compared to that of others; their markedly loo values are difficult to explain by the method us or the physical characteristics of the subjects.

The value for $\mathrm{FEV}_{1} / \mathrm{FVC} \%$ appears to be altered little during growth in the age grou估 studied. This finding agreed with that of Stran

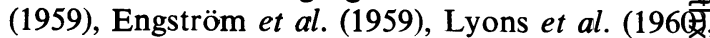
and Bjure (1963). Although both Strang and Bjure found a significant difference between the values of this measurement in males and females this was not so in the present study. There was slight difference between the present value for $\mathrm{FEV}_{1} / \mathrm{FVC} \%$ and those mentioned already (Bjure, 1963 ; Engström et al., 1959 ; Lyons et a 1960 ; Strang, 1959); however, this very sma difference might have been caused by the metho employed and seemed to be of such little clinic importance that further statistical analyses were not done.

RV/TLC \% showed no significant relationship to age or sex. This result supports those of Engström et al. (1956) and Needham et al. (1954. who studied children 6-14 and 11-19 years of age respectively. Although there was a slight diffeg

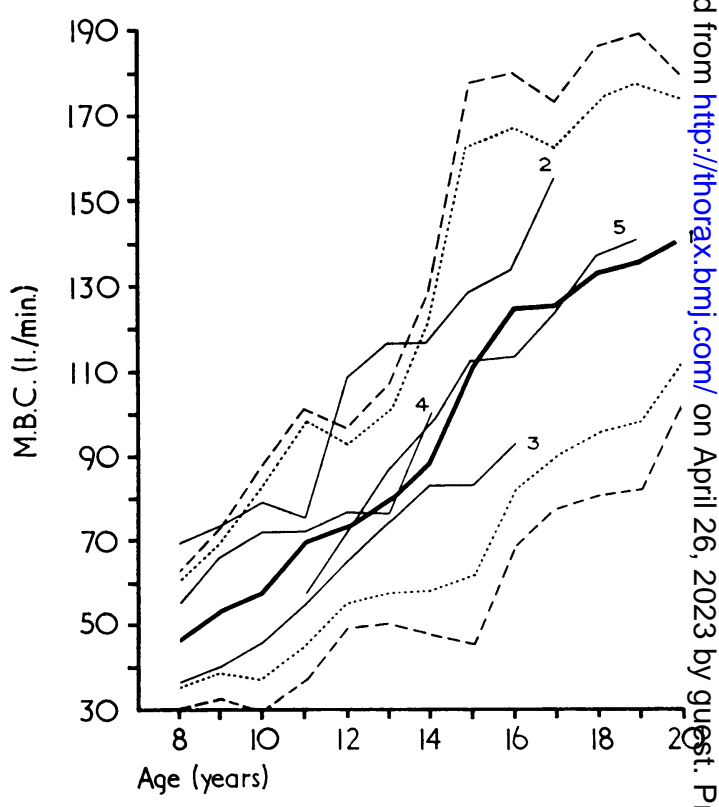

FIG. 6. Relationship of maximal breathing capacity $\bar{q}$ males to age. Comparison of mean values with those o\$ other authors. Dashed and dotted lines as in Figure 4 1, Present study; 2, Ferris et al. (1952); 3, Tatai (1955) 4, Kennedy et al. (1957); and 5, Needham et al. (1954). 
ence between the present values and those of Needham et al. (males, 24.9 \pm 4.7 ; females, $25 \cdot 7 \pm 4 \cdot 7)$ and Engström et al. (1956) $(21 \cdot 7 \pm 2 \cdot 95$ for both sexes), the difference is not considered clinically important.

When the mean values for maximal breathing capacity obtained from the literature and present values were plotted on a graph versus age (Figs 6 and 7), there was, in general, good agreement

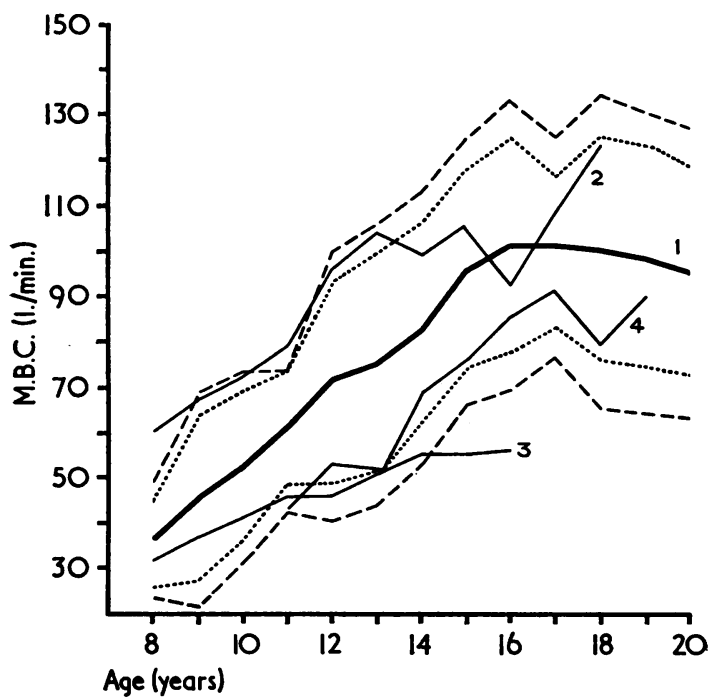

FIG. 7. Relationship of maximal breathing capacity of females to age. Comparison of mean values with those of other authors. Dashed and dotted lines as in Figure 4. 1, Present study; 2, Ferris and Smith (1953); 3, Tatai (1955); and 4, Needham et al. (1954).

between them. Almost all curves were within the $95 \%$ confidence limits of the present study. Again, the values of Ferris and Smith (1953) and Ferris et al. (1952) were higher than others for both sexes and the lowest values were obtained by Tatai (1955). These relatively higher and lower values may be explained by the same reasons that were mentioned for vital capacity.

The writers thank Dr. J. I. E. Hoffman, Cardiovascular Research Institute, University of California, San Francisco Medical Center, for valuable help with the statistical analyses, and Miss Laura Schmid, from the Computer Center, University of California San Francisco Medical Center, for help in obtaining computer analyses of the data.

This work was supported in part by the Ege University Research Grant $963 / 3$.

\section{REFERENCES}

Baldwin, B. T. (1928). Breathing capacity according to height and age of American-born boys and girls of school age. Amer.J. phys. Anthrop., 12, 257.

Bhattacharya, A. K., and Banerjee, S. (1966). Vital capacity in children and young adults of India. Indian J. med. Res., 54, 62.

Bjure, J. (1963). Spirometric studies in normal subjects. IV. Ventilatory capacities in healthy children 7-17 years of age. Acta Pediat. (Uppsala), 52, 232.

Comroe, J. H., Forster, R. E., DuBois, A. B., Briscoe, W. A., and Carlsen, E. (1962). The Lung, Clinical Physiology and Pulmonary Function Tests. 2nd ed. Year Book Medical Publishers, Chicago.

Dreyer, G. (1919). Investigations on the normal vital capacity in man and its relation to the size of the body. Lancet, 2, 227.

Du Bois, D., and Du Bois, E. G. (1916). Clinical calorimetry. A formula to estimate the approximate surface area if height and weight be known. Arch. intern. Med., 17, 863.

Emerson, P. W., and Green, H. (1921). Vital capacity of the lungs of children. Amer. J. Dis. Child., 22, 202.

Engström, I., Karlberg, P., and Kraepelien, S. (1956). Respiratory studies in children. I. Lung volumes in healthy children, 6-14 years of age. Acta Pediat. (Uppsala), 45, 277.

- and Wengler, G. (1958). Respiratory studies in children. V. Maximal breathing capacity in healthy and in symptom-free asthmatic children, 7-14 years of age. Ibid., 47, 560 .

- Escardo, F. E., Karlberg, P., and Kraepelien, S. (1959). Respiratory studies in children. VI. Timed vital capacity in healthy children and in symptom-free asthmatic children. Ibid., 48, 114.

Ferris, B. G., and Smith, C. W. (1953). Maximum breathing capacity and vital capacity in female children and adolescents. Pediatrics, 12, 341 .

- Whittenberger, J. L., and Gallagher, J. R. (1952). Maximum breathing capacity and vital capacity of male children and adolescents. Ibid., 9, 659 .

Jones, H. E. (1955). The vital capacity of children. Arch. Dis. Childh., 30,445 .

Kennedy, M. C. S., Thursby-Pelham, D. C., and Oldham, P. D. (1957) Pulmonary function studies in normal boys. Ibid., 32, 347.

Lyons, H. A., Tanner, R. W., and Picco, T. (1960). Pulmonary function studies in children. Amer. J. Dis. Child., 100, 196.

Morse, M., Schlutz, F. W., and Cassels, D. E. (1952). The lung volume and its subdivisions in normal boys 10-17 years of age. J. clin. Invest., 31, 380.

Needham, C. D., Rogan, M. C., and McDonald, I. (1954). Normal standards for lung volumes, intrapulmonary gas-mixing, and maximum breathing capacity. Thorax, 9, 313.

Stewart, C. A. (1922). The vital capacity of the lungs of children in health and disease. Amer.J. Dis. Child., 24, 451 .

Strang, L. B. (1959). The ventilatory capacity of normal children. Thorax, 14, 305.

Tatai, K. (1955). Vital capacity, maximum breathing capacity, and maximum breathing rate of Japanese children and adolescents. Jap. J. Physiol., 5, 217.

Turner, J. A., and McLean, R. L. (1951). Spirometric measurements of lung function in healthy children. Pediatrics, 7, 360.

West, H. F. (1920). Clinical studies on the respiration. VI. A comparison of various standards for the normal vital capacity of the lungs. Arch. intern. Med., 25, 306. 